\title{
Endothelial progenitor cell biology in disease and tissue regeneration
}

\author{
Andrea L George, Pradeep Bangalore-Prakash, Shilpi Rajoria, Robert Suriano, Arulkumaran Shanmugam, \\ Abraham Mittelman and Raj K Tiwari
}

\begin{abstract}
Endothelial progenitor cells are increasingly being studied in various diseases ranging from ischemia, diabetic retinopathy, and in cancer. The discovery that these cells can be mobilized from their bone marrow niche to sites of inflammation and tumor to induce neovasculogenesis has afforded a novel opportunity to understand the tissue microenvironment and specific cell-cell interactive pathways. This review provides a comprehensive up-to-date understanding of the physiological function and therapeutic utility of these cells. The emphasis is on the systemic factors that modulate their differentiation/mobilization and survival and presents the challenges of its potential therapeutic clinical utility as a diagnostic and prognostic reagent.
\end{abstract}

Keywords: Endothelial Progenitor Cells, Neovascularization, Estrogen, Cancer, Proangiogenic proteins, Inflammation, Tumor Microenvironment, Cluster of Differentiation Antigens, Chemokines

\section{Introduction}

As a new decade of cancer research begins, many of the same problems in investigating tumor growth and metastasis remain. Much of the difficulty is due to the heterogeneity of not only the tumor types, but the cellular environment of the individual tumors themselves. All cancers though still go through specific initiation, promotion, and progression phases. The initiation events are varied from endogenous metabolites to exogenous insults while the tumor microenvironment in part dictates the promotion and progression phases. The unanswered questions of why some tumors remain benign while others become malignant, why some only grow at their primary foci while others rapidly metastasize, and why some are susceptible to chemotherapeutics while others remain resistant is still an enigma. These differences have lead researchers to develop new strategies of cancer treatment aimed at the body's normal physiological processes that tumors are able to manipulate to their own end.

One recent strategy that has emerged in cancer research involves targeting of tumor associated blood vessels which provide growing tumors with oxygenated blood and growth factors necessary for maintenance and

\footnotetext{
* Correspondence: raj_tiwari@nymc.edu

* Correspondence: raj_tiwari@nymc.edu
Department of Microbiology and Immunology, New York Medical College, Valhalla, New York, USA
}

(c) 2011 George et al; licensee BioMed Central Ltd. This is an Open Access article distributed under the terms of the Creative Commons Attribution License (http://creativecommons.org/licenses/by/2.0), which permits unrestricted use, distribution, and reproduction in any medium, provided the original work is properly cited. metastasis. The uncontrolled growth of tumors leads to formation of a hypoxic tumor microenvironment leading to a proangiogenic signalling cascade. Initial work was focused on tumor induced angiogenesis, or sprouting of existing vasculature toward the tumor. However, recent research has identified a novel mechanism in vasculature development known as vasculogenesis, or the formation of new vessels from bone marrow derived progenitor cells rather than sprouting or elongation of existing vessels. Neovasculogenesis is due, in part, to bone marrowderived endothelial progenitor cells (BM-EPCs) which are released from the marrow and home to sites of blood vessel formation.

While the rapid expansion of cells leads to activation of neovascularization, the process relies on the formation of a hypoxic, and thus inflammatory, tumor microenvironment that signals not only for progenitor but also immunomodulatory cell migration. Secretion of proangiogenic as well as both pro and anti-inflammatory cytokines by these modulating cells also influences the genetic and phenotypic characteristics of tumor cells. Such cytokines include IL- 1 and TGF- $\beta$ which lead to an epithelial to mesenchymal transition (EMT) during which tumor cells downregulate epithelial markers including E-cadherin and upregulate mesenchymal markers as well as transcription factors like SNAIL and TWIST increasing their 
metastatic propensity [1-3]. Inflammation, also induced by cytokines secreted by infiltrating macrophages, alters the tumor cell epigenome and modulation of proangiogenic proteins [4]. Tumor cell development is comparable to a "wound" that never heals in which a steady inflammatory environment is propagated. Future work must also be directed toward the influx of immunomodulating cells and their cytokine profile.

We however have identified another mechanism of BM-EPC induced vasculogenesis, in which progenitor cells contribute to the development of breast tumor vessel formation in an estrogen dependent manner [5]. Indeed, clinically circulating EPCs are being correlated with increased tumor growth and since they home to tumor sites are being targeted as potential Trojan Horses for specific gene therapy delivery [6]. Identification of this novel cell type's role in neovasculogenesis may provide researchers a common target for anti-tumor therapy directed against the tumor and the tumor microenvironment. This review, while focusing on the difference between angiogenesis and vasculogenesis, the characteristics of the bone marrow derived progenitor cells that contribute to neovasculogenesis, and the factors that modulate them, places the process of neovasculogenesis as a necessary modulator of the tumor microenvironment capable of promoting a subset of tumor cells which are responsible for tumor progression.

\section{Angiogenesis vs. Vasculogenesis}

Angiogenesis is the formation of new vessels from existing vasculature by two distinct methods termed sprouting and non-sprouting angiogenesis. Sprouting angiogenesis (SA) occurs when endothelial cells migrate and divide off the existing vessels and fusion of vacuoles within the endothelial cells creates the vascular lumen [7]. Migration of these cells relies on a source of proangiogenic stimuli as well as proteases that degrade the basement membrane which allows mobilization and proliferation of endothelial cells that later form sprouts. Non-sprouting angiogenesis, or intussesceptive angiogenesis (IA), occurs via splitting of an already existing vessel into two by formation of transcapillary pillars followed by vascular myogenesis, although the exact mechanism is poorly understood [7]. Angiogenesis is necessary during embryonic development but also plays important roles throughout postnatal life in wound healing, tissue ischemia, and tumor vasculature formation and is now a major therapeutic target in cancer treatment.

However, recent studies have shown that a mechanism different from angiogenesis exists for formation of vessels in adults called postnatal vasculogenesis or neovascularization. During vasculogenesis precursor cells from adult bone marrow are mobilized into circulation in response to various signals and home to the source where they differentiate into mature endothelial cells, assisting in the ongoing vascular development [8]. Neovascularization is a critical process for revascularization of ischemic tissues and wound healing but plays a role pathologically as it can be induced by cancers to aid in tumor growth and metastasis, and can also be seen in conditions like diabetic retinopathy and retinopathy of prematurity [8]. The bone marrow precursor cells that aid in neovascularization are known as endothelial progenitor cells.

\section{EPCs: Physiological and Biological Functions}

Endothelial progenitor cells (EPCs) are bone marrow derived cells that can be found in the peripheral and umbilical cord blood and were first isolated using magnetic micro beads by Asahara [9]. Studies have shown that the term 'EPCs' cannot be used to define a single cell type but rather should be used to refer to multiple cell types capable of differentiating into the endothelial lineage [10]. First, they are considered derivatives of hemangioblasts and express CD34, VEGFR-2 and CD133 on their surface (Table 1). CD133, a transmembrane, $120 \mathrm{kDa}$ glycoprotein, is expressed by EPCs but not by mature endothelial cells. These adult EPCs and the embryonic angioblasts share similar characteristics as both are derived from the hemangioblast precursors and both have the capacity to home to the periphery where they proliferate and differentiate into mature endothelial cells. Second, EPCs are considered one subset of cells derived from bone marrow multipotent adult progenitor cells (MAPCs). MAPCs also express CD133 and VEGFR-2 but lack CD34 or vascular endothelial cadherin expression [10]. In vitro experiments on MAPCs have shown that they differentiate into mature endothelial cells when grown in a serum-free media with VEGF (Table 1). Lastly, the myelo/monocytic cells, also derived from the bone marrow, can differentiate into EPCs [10]. The myelo/monocytic cells express CD14 on their surface and form mature endothelial cells positive for vWF, VEGFR-2, and CD45 (common leukocyte antigen) expression when cultured (Table 1). Irrespective of their origin, EPCs in general have the functional ability to take up acetylated LDL, and bind to Ulex europaeus agglutinin 1 (UEA1) [11]. Hence, in vivo three groups of progenitors have been found to differentiate into mature endothelial cells, the hemangioblasts, the MAPCs and the myelo/ monocytic cells. Two groups of EPCs have been defined in in vitro models, the early EPCs, which are derived from the monocytes and have surface expression of CD45, CD14, CD11b and CD11c, and the late EPCs, which are believed to be a subset of $\mathrm{CD} 14^{-} \mathrm{CD} 34^{-} \mathrm{KDR}^{-}$(kinase insert domain protein receptor) cells that do not express CD45 or CD14 [12].

Studies of EPC modulation and function require their isolation and expansion. EPCs are obtained from ex vivo/ in vitro culture of unfractionated peripheral blood mononuclear cells (MNCs) or by direct flushing of bone marrow 
Table 1 Cell surface markers that functionally define EPCs

\begin{tabular}{|c|c|c|}
\hline Surface Markers & Function & Cell Expression \\
\hline CD34 & $\begin{array}{c}\text { Glycoprotein important for cell-cell adhesion, maintenance of } \\
\text { stem cells in bonemarrow, mediates attachment of leukocytes } \\
\text { to high endothelial venules [57] }\end{array}$ & $\begin{array}{c}\text { Hemangioblasts, Endothelial Progenitor Cells, Vascular } \\
\text { Endothelial Cells [10] }\end{array}$ \\
\hline VEGFR-1 (Flt1) & $\begin{array}{l}\text { Tyrosine kinase receptor for VEGF A and B, important for } \\
\text { endothelial cell assembly into vessels [58] }\end{array}$ & $\begin{array}{l}\text { MAPC, Myelo/Monocytic Progenitors, Vascular Endothelial } \\
\text { Cells [58] }\end{array}$ \\
\hline VEGFR-2 (FIk1, KDR) & $\begin{array}{l}\text { Tyrosine kinase receptor for VEGF A,C,D,\&E, critical for } \\
\text { hematopoietic and endothelial cell development, principal } \\
\text { mediator of VEGF-A mitogenic and pro-migration ability [59] }\end{array}$ & $\begin{array}{c}\text { Hemangioblasts, Endothelial Progenitor Cells, MAPC, } \\
\text { Myelo/Monocytic Cells, Vascular Endothelial Cells, } \\
\text { Lymphatic Endothelial Cells [10] }\end{array}$ \\
\hline CD133 (Prominin 1) & $\begin{array}{l}\text { Membrane glycoprotein, function unknown, serves as a marker } \\
\text { for hematopoietic and endothelial progenitor cells [60] }\end{array}$ & Hematopoietic Cells, Endothelial Progenitor Cells [10] \\
\hline CD45 & $\begin{array}{l}\text { Protein tyrosine phosphatase, important for lymphocyte } \\
\text { activation via LCK and FYN [61] }\end{array}$ & Cells of Hematopoietic System [61] \\
\hline VE-cadherin & $\begin{array}{c}\text { Calcium dependent glycoprotein, intercellular junction protein } \\
\text { necessary for proper vascular development [62] }\end{array}$ & Mature Endothelial Cells [62] \\
\hline VWF & Secreted glycoprotein important for platelet aggregation [63] & $\begin{array}{c}\text { Produced by Endothelial Cells and Megakaryocytes, Stored } \\
\text { in Platelets }[10,63]\end{array}$ \\
\hline
\end{tabular}

and expansion in endothelial specific media. Only two different cell types have been isolated from the cultures so far, the endothelial cell-like cells (EC-like cells), and the endothelial outgrowth cells (EOCs). These two cell types have few similarities; they can effect neovascularization in vivo, take up LDL by binding UEA-1 lectin and have similar surface markers such as CD31, vWF $[13,14]$. However, the EC-like cells are derived from $\mathrm{CD} 45^{+}$hematopoietic lineage cells, they are spindle shaped and are generated after 4-21 days in culture, they have a low proliferative potential and do not produce vascular tubes in vitro. In vivo they have myeloid progenitor cell activity and differentiate into macrophages but they do not form vessels $[13,14]$. Although they are unable to form vessels directly, they have an indirect paracrine effect on angiogenesis by secreting angiogenic factors locally. Hence, these cells are not considered true EPCs but can be referred to as 'Angiogenic cells' [13]. The EOCs, unlike the EC-like cells, originate from $\mathrm{CD} 45^{-} \mathrm{CD} 133^{-} \mathrm{CD}^{-} 4^{+}$cells and do not have hematopoietic surface markers. EOCs express CD31, CD34, CD105, CD146, VE-Cadherin, and VEGFR-2 on their surface. In cultures they are polygonal cells and appear after 7 days, they are highly proliferative, and they do not differentiate into hematopoietic cells. The EOCs can form vessels both in vitro and in vivo [13].

To aid in neovasculogenesis, EPCs mobilize from the bone marrow in response to endogenous or exogenous signals and home to peripheral tissue sites. Their surface receptor P-selectin glycoprotein ligand-1(PSGL-1) interacts with P-selectin and E-selectin expressed on endothelial cells, followed by autocrine and paracrine activation of EPCs resulting in differentiation or transdifferentiation, proliferation and vascular growth [12]. $\beta 2$ integrins (LFA-1, Mac-1) and $\beta 1$ integrin also mediate homing of the EPCs to the periphery and $\beta 2$ integrin helps in the arrest and migration of EPCs across the endothelial cells [15]. The physiological function of circulating EPCs is to maintain vascular integrity which is also crucial in the pathogenesis of various diseases with vascular insult. The vasculogenic potential of EPCs is also exploited by tumors by recruiting EPCs to facilitate their growth and metastasis [12].

EPCs are not only involved in physiological neovascularization but also involved in wound healing, tissue regeneration in ischemia (e.g. myocardial ischemia, limb ischemia), tissue remodelling (Diabetes mellitus and Heart failure) and neovascularization and growth of tumors [16]. EPCs are mobilized from the bone marrow in response to paracrine signals generated by ischemic tissue and tumor cells including GM-CSF and VEGF, which play a critical role in mobilization of EPCs to ischemic tissues and tumors. Hypoxia in tumors and ischemic tissues mediate EPC recruitment by activation of HIF-1 which leads to increased synthesis of a potent angiogenic factor VEGF. Also growing tumors secrete a number of other factors like fibroblast growth factor (FGF), SDF-1, osteopontin, CCL2 and CCL5 which help in EPC mobilization [17]. EPCs are then released into circulation by activation of MMP-9 which degrades the extracellular matrix and transforms membrane-crossing Kit ligand (mKitL) to solubility Kit ligand (sKitL) in the bone marrow [18,19] (Figure 1). The physiological function of circulating EPCs is to maintain vascular integrity which is also crucial in the pathogenesis of various diseases with vascular insult. The vasculogenic potential of EPCs is also exploited by tumors by recruiting EPCs to facilitate their growth and metastasis [12]. The tumor microenvironment plays a major role in activating circulating EPCs and mediating neovascularization and stressors in the tumor microenvironment such as hypoxia, 


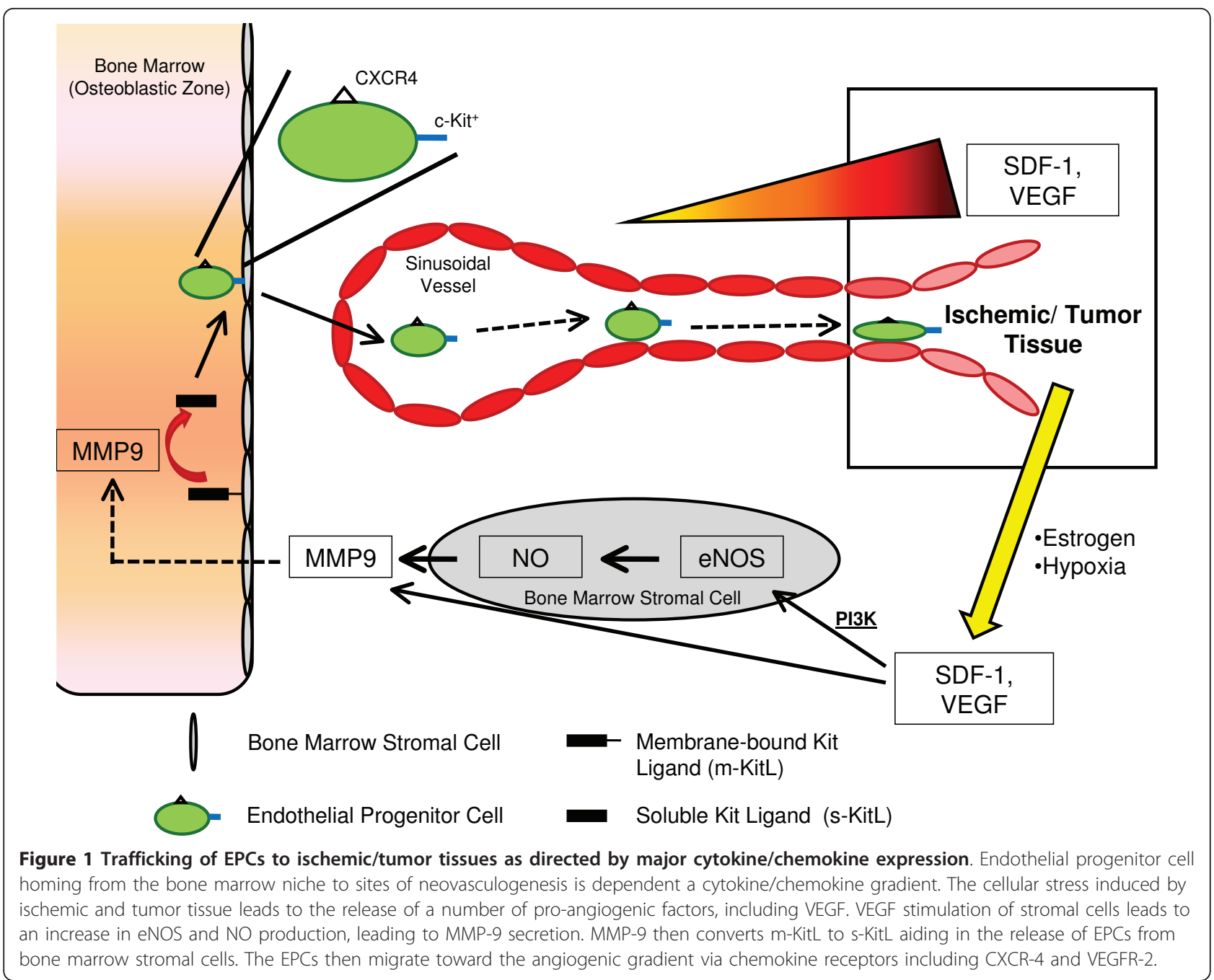

glucose deprivation, and reactive oxygen species upregulate transcription of angiogenic factors like VEGF, SDF-1, MCP-1, and erythropoietin in EPCs [12,20,21]. Also CCL11 mediates tumor angiogenesis by recruitment and activation of eosinophils which secrete angiogenic factors [22].

Tumor growth has an avascular and vascular phase, and it is in the avascular phase of tumor growth and ischemic tissue that hypoxia induced EPC mobilization is active [20,21]. The EPCs recruited to the tumor or ischemic sites have a direct structural function by forming the vessel or an indirect paracrine effect by secreting angiogenic factors. The role of EPCs in tumor neovascularization was studied in an Id1 +/- Id3-/- mouse model which is tumor resistant and has defective angiogenesis, where transplantation of wild type bone marrow to the mutant mice restored tumor angiogenesis and growth. In the same study they also found that both VEGFR1 and VEGFR2 are required for tumor growth and blocking these receptors together completely abolishes tumor growth [23]. Mobilization and incorporation of EPCs in tumor vessels varies with the tumor type, tumor stage and tumor treatment. Studies on different types of tumors and EPCs have shown an increase in the circulating EPC population in lymphomas, leukemia, hepatocellular carcinoma, and colon cancer. Because of this EPCs have a diagnostic, therapeutic and prognostic potential in cancers. EPCs can thus act as biomarkers of tumor development and/or progression and can be studied by injection of labelled AC133+ cells and tracking it with MRI. EPCs are known to home to tumor tissues, and this property allows their use as a therapeutic delivery vehicle in combination with targeted anti-angiogenic or cytotoxic effects. EPCs are also used as gene delivery vehicles to tumor tissues $[20,24]$. The physiological significance of EPCs is varied and is of relevance in both normal and tumor tissue regeneration. Clinical exploitation of these cells is critically dependent on the biology of its modulators both systemic and cell derived soluble proteins. 


\section{Modulation of EPC Functions}

EPC homing relies on creation of a gradient of endogenous proteins. One of the best studied is vascular endothelial growth factor (VEGF), a homodimeric glycoprotein with a molecular weight of $45 \mathrm{kDa}$ which is synthesized by normal cells and upregulated by hypoxia. VEGF is not only secreted locally where it has paracrine like effects but is also secreted into circulation and acts as a hormone [25]. Under hypoxic conditions transcription factors like Hypoxia Inducible Factor - 1 (HIF-1) are activated leading to increased transcription of VEGF [24]. VEGF stimulates VEGFR1 and VEGFR2 receptors present on endothelial and hematopoietic stem cells and activates matrix metalloproteinase - 9 (MMP-9) which in turn cleaves and activates Kit ligand (KitL) and induces proliferation and migration of EPCs and hematopoietic cells [26].

The proangiogenic protein angiogenin also plays a role in EPC function. Angiogenin is a $14-\mathrm{kDa}$ protein that binds and activates endothelial cells leading to proliferation and migration and has ribonucleolytic activity. Angiogenin also translocates to the nucleus of cells, which is necessary for other proteins, including VEGF, to exert their proangiogenic effects [27]. Angiogenin may bind with follistatin, another angiogenic protein that in an in vivo model was found to increase the number of tumor associated capillaries but not tumor size [28,29].

Another family of angiogenic factors is the Angiopoietins (Ang-1, 2), $57 \mathrm{kDa}$ proteins that regulate both neoplastic and non neoplastic neovasculogenesis in the embryo and post natal life and mitigate their effects by binding cognate tyrosine kinase receptors (Tie-1 and Tie2 ). Ang-1 can activate the receptor Tie- 2 and lead to downstream activation of the phosphatidylinositol 3'kinase/Akt prosurvival pathway in endothelial cells. In vivo however, studies on Ang-1 have showed that over expression of Ang-1 in tumors decreases tumor neovascularization and tumor size [30]. The function of Ang-2 still remains controversial, as early models suggested Ang-2 was a functional antagonist of Ang-1, however, a role of Ang-2 in vessel sprouting has been identified [31,32].

Cytokines also promote EPC mobilization to the periphery. Granulocyte-colony stimulating factor (G-CSF) and granulocyte monocyte-colony stimulating factor (GM-CSF) are glycoproteins which stimulate production of granulocytes in the bone marrow, and also influence the proliferation, differentiation, and migration of bone marrow EPCs [33]. Another cytokine that may play a role in EPC modulation includes IL-8. Binding of IL-8 to human umbilical vein endothelial cells (HUVECs) that express the receptors CXCR1 and CXCR2 lead to endothelial cell proliferation and capillary tube formation in vitro [34]. Further, in acute myocardial infarction, IL-8 was associated with an increase in circulating CD133+ cells [35]. Taken together with the fact that breast cancer patients in higher stages had significantly more IL-8 mRNA may shed light on a novel role of IL- 8 on progenitor cell mediated neovascularization [36].

Chemokines and their receptors are involved in EPC migration and differentiation as well. CCR2 is a chemokine receptor expressed on the surface of EPCs and vascular smooth muscle cells (VSMCs) that mediates chemotaxis to areas of endothelial denudation, which secrete monocyte chemoattractant protein-1 (MCP-1/ CCL2), leading to angiogenesis [37]. EPCs also express another chemokine receptor CCR5 which binds its ligand RANTES/CCL5 and plays an important role in atherogenesis and vascular remodelling [37]. CXCL12 or stromal cell derived factor $-1 \alpha(\mathrm{SDF}-1 \alpha)$ is another chemokine responsible for EPC mobilization and also recruitment along hypoxic gradients via the CXCR4 receptor. During tumor growth, hypoxic regions stimulate the transcription factor hypoxia inducible factor 1 (HIF-1) leading to transcription of proangiogenic proteins including VEGF and SDF-1 $\alpha$ [38]. Formation of the SDF- $1 \alpha$ gradient leads to mobilization of EPCs. Further, chemotaxis of EPCs toward SDF- $1 \alpha$ is increased by IL- 3 and EPCs derived from the bone marrow respond better than those isolated from circulation [39]. The chemokine eotaxin or CCL11 mediates angiogenesis either directly via the CCR3 receptor of human microvascular endothelial cells or indirectly by recruitment and activation of eosinophils which release angiogenic factors like transforming growth factor $\alpha$ and $\beta$ (TGF- $\alpha$, TGF- $\beta$ ) [22]. Chemokine CXCL1 and its receptor CXCR2 are involved in endothelial repair after injury. Recently, activated platelets have been implicated in EPC recruitment and migration via release of $\beta$-thromboglobulin, a precursor CXCL12 and CXCL7 [15].

Recent studies involving endothelial nitric oxide synthase have showed that nitric oxide (NO) plays an important role in angiogenesis involving mature endothelial cells and neovasculogenesis involving EPCs [40]. In models of mice deficient in endothelial nitric oxide synthase $\left(\mathrm{NOS}^{-1-}\right)$, VEGF stimulation of EPC mobilization was reduced and only intravenous infusion of wild type progenitor cells, not bone marrow transplantation, resulted in restoration of neovascularization, demonstrating the role of nitric oxide in mobilization of progenitor cells into circulation [41]. In rat bone marrow ex vivo models, administration of angiotensin II lead to eNOS dependent NO production in EPCs and modulated EPC adhesion and apoptosis [42].

Exogenous factors, including drugs like Statins and Thiazolidinediones are also involved in EPC migration and proliferation. Statins are drugs which inhibit the enzyme 3-hydroxy-3-methylglutryl coenzyme A (HMG-CoA) 
involved in cholesterol biosynthesis. They also activate both endothelial progenitor cells and mature endothelial cells by stimulation of the Akt signalling pathway [43]. Endogenous factors used therapeutically like G-CSF and GM-CSF, used to treat haematological diseases, are known to induce BM-EPCs mobilization and migration and may present further complications. The factors listed above utilize prosurvival chemokine/cytokine mediators for cellular modulation. We and others discovered the presence of estrogen receptor in EPCs suggesting a novel role of the E2-ER pathway in the survival and biological activities of EPCs.

\section{Role of ER on EPC neovascularization}

Epidemiological observations have indicated a role of hormones, specifically estrogen, in vascular repair and maintenance. Such observations include a comparative decrease of heart disease and increase in vascular repair in women compared to men. Initial work focused on the role of estrogen in ischemic tissue and heart models found that estrogen is indeed cardio protective and aids in vascular repair. One such mechanism is via upregulation of prostacyclin in endothelial cells leading to vasodilation and inhibiting platelet aggregation [44,45]. In vivo studies using estrogen receptor $\alpha$ and $\beta$ knockout mice have verified that estrogen and its receptors are important specifically in EPC dependent neovascularization of ischemic tissue. The activation of EPCs by estradiol is predominantly mediated via ER $\alpha$, and EPCs treated with estradiol showed an increased expression of ER $\alpha$ mRNA transcripts. Further, VEGF expression was increased in treated WT EPCs whereas VEGF expression was minimal in ER $\alpha$ knock out EPCs [46]. Estrogen activates EPCs via the PI3K/Akt pathway, phosphotidlyinositol-3 kinase (PI3K) converts PIP2 to PIP3, PIP3 in turn phosphorylates Akt which is responsible for EPC migration and proliferation [47]. Estrogen also increases the telomerase activity in EPCs and prolongs their survival [48]. Interestingly, in mice deficient for eNOS expression, estradiol has no effect of EPC mobilization, indicating a major role of nitric oxide in EPC function [49]. Estrogen also exerts effects on nonischemic EPC aided vascularization, for example previous work observed a cyclical increase in EPC mobilization following a rise in estrogen and VEGF levels during menstrual cycling in uterine tissue [50,51].

Recently, the role of estrogen in tumor induced neovascularization has emerged lending focus to its ability to significantly impact not only tumor growth and development but also metastasis. Previously, our lab observed an increase in BM-EPC mobilization and homing to tumor tissue in an in vivo transgenic mouse breast tumor model when mice were supplemented with a slow release estradiol pellet. This supplementation lead not only to an increase in tumor vessel formation but also an increase in mRNA transcripts of proangiogenic genes including angiopoietins 1 and 2, MMPs 2 and 9, and VEGF [5]. Using transgenic animals in which GFP was under control of the Tie2 (TEK) promoter, we were able to visualize BM-EPC association with tumor blood vessels. Further, in an in vitro model tumor cell conditioned media from estradiol supplemented cells also lead to BM-EPC tubulogenesis when compared to control conditioned media [5]. Thus, hormones, in particular estrogen, play a large role in EPC function and are pivotal in tumor development in hormone responsive tissues. It is this novel mechanism of estrogen mediated tumor progression that will be the aim of future therapeutic strategies.

\section{Potential for future work}

While the major physiological role of circulating EPCs in adults is to maintain vascular integrity, they can also home to and aid in revascularization of ischemic and tumor tissues [7]. Indeed previous clinical correlations have reported an increase in EPC circulation in breast, ovarian and pancreatic cancer patients with a positive correlation to tumor stage and size $[6,52,53]$. It is this observation that may prove EPC's usefulness as a biomarker for early tumor detection where EPCs serve as a sensor of tumor initiation. Further, tagging of EPCs may allow tracing of their mobilization and homing to tumor tissues aiding in specific, targeted early detection of tumor growth, a critical determinant of aggressive tumor growth outcome.

This targeted homing can be manipulated for future therapeutic research. One such method may utilize EPCs as gene delivery vehicles in the treatment of tumors. Such a method would involve ex vivo expanded EPCs that can be transduced with a transgene expressing anti-angiogenic factors and administered to patients directed at blocking tumor growth [54]. Drug delivery vehicles currently used to deliver chemotherapeutic drugs to the tumors are liposomes and exosomes, analogous to these, EPCs can be used as a 'Trojan horse' for targeted delivery of drugs to tumor tissues. Another potential therapeutic strategy aimed at blocking EPC mobilization and migration from the bone marrow itself would also impact tumor growth and metastasis and may increase efficacy of early detection and surgical intervention [20].

While the methods described may prove EPCs as powerful weapons against cancer development, their role in other physiological functions also needs consideration. EPCs have a possible therapeutic benefit in ischemic diseases as injection of ex vivo expanded EPCs into patients may have potential regenerative effects in ischemic tissues opening the door to novel treatment strategies for diabetes. EPCs may also be used to construct endothelial coated vascular grafts which may have 
a better patency rate [55]. On the negative side increasing the number of circulating EPCs to promote neovasculogenesis in ischemia should be investigated for plaque destabilization and differentiation into atherogenic cells which can cause embolism [56].

\section{Conclusions}

Endothelial Progenitor cells originate from the bone marrow and have the ability to differentiate into multiple cell lines. Endogenous factors like VEGF, cytokines, estradiol, and eNOS with exogenous factors like statins and thiazolidinediones mediate recruitment of EPCs into the circulation. Circulating EPCs have a wide array of functions in tissue regeneration, tissue remodelling and cancer progression. In tumors and ischemic tissues EPCs have a direct structural role of differentiating into mature endothelial cells and an indirect paracrine effect by secreting angiogenic factors. Hypoxia in ischemic tissues and during the early phase of tumor growth is crucial for EPC recruitment and is mediated via upregulation of HIF-1 leading to an increase in the transcription of proangiogenic proteins including VEGF. EPCs also play a major role in the pathogenesis of heart failure, diabetes and vascular diseases with studies showing that high circulating EPCs have a direct correlation with decreased vascular complications. Further research to study the biology of EPCs is essential and ultimately will lead to the development and utilization of EPCs as a powerful diagnostic, therapeutic and prognostic tool in a wide variety of diseases.

\section{List of abbreviations used}

BM-EPCS: bone marrow-derived endothelial progenitor cells; IL-1: interleukin 1; TGF-a/B: transforming growth factor alpha/beta; EMT: epithelial to mesenchymal transition; SA: sprouting angiogenesis; IA: intussesceptive angiogenesis; VEGF: vascular endothelial growth factor; VEGFR: vascular endothelial growth factor receptor; MAPCs: multipotent adult progenitor cells; vWF: vonWillebrand factor; LDL: low-density lipoprotein; UEA1: Ulex europaeus agglutinin 1; KDR: kinase insert domain protein receptor; MNCs: mononuclear cells; EOCs: endothelial outgrowth cells; PSGL-1: P-selectin glycoprotein ligand-1; LFA-1: lymphocyte function-associated antigen 1; FGF: fibroblast growth factor; SDF-1: stromal derived factor 1; mKitL: membranecrossing Kit ligand; sKitL: solubility Kit ligand; MCP-1: monocyte chemoattractant protein-1; MRI: magnetic resonance imaging; HIF-1: hypoxia inducible factor 1; MMP: matrix metalloproteinase; G-CSF: granulocyte-colony stimulating factor; GM-CSF: granulocyte monocyte-colony stimulating factor; HUVECs: human umbilical vein endothelial cells; VSMCs: vascular smooth muscle cells; RANTES: regulated upon activation, normal T-cell expressed and secreted; NO: nitric oxide; NOS3 (eNOS): nitric oxide synthase 3 (endothelial nitric oxide synthase); HMG-CoA: 3-hydroxy-3-methylglutryl coenzyme A; ERa: estrogen receptor alpha; PI3K: phosphatidylinositol 3-kinases; PIP2: phophatidylinositol bisphosphate; PIP3: phophatidylinositol $(3,4,5)$ triphosphate; WT: wild type

\section{Acknowledgements}

This work was supported by a grant from the National Cancer Institute 1R01CA131946.

\section{Authors' contributions}

ALG, PBP, SR, RS, AS, AM, RKT involved in concept design, coordination, drafting and critically revising the manuscript and have given final approval.

\section{Competing interests}

The authors declare that they have no competing interests.

Received: 1 April 2011 Accepted: 24 May 2011 Published: 24 May 2011

\section{References}

1. Lindley LE, Briegel KJ: Molecular characterization of TGFbeta-induced epithelial-mesenchymal transition in normal finite lifespan human mammary epithelial cells. Biochem Biophys Res Commun 2010, 399(4):659-664.

2. St John MA, Dohadwala M, Luo J, Wang G, Lee G, Shih H, Heinrich E, Krysan K, Walser T, Hazra S, Zhu L, Lai C, Abemayor E, Fishbein M, Elashoff DA, Sharma S, Dubinett SM: Proinflammatory mediators upregulate snail in head and neck squamous cell carcinoma. Clin Cancer Res 2009, 15(19):6018-6027.

3. Foubert E, De Craene B, Berx G: Key signaling nodes in mammary gland development and cancer. The Snail1-Twist1 conspiracy in malignant breast cancer progression. Breast Cancer Res 2010, 12(3):206-217.

4. Coomber BL, Yu JL, Fathers KE, Plumb C, Rak JW: Angiogenesis and the role of epigenetics in metastasis. Clin Exp Metastasis 2003, 20(3):215-227.

5. Suriano $R$, Chaudhuri $D$, Singh Johnson R, Lambers E, Ashok BT, Kishore R, Tiwari RK: $17 \beta$-Estradiol mobilizes bone marrow-derived endothelial progenitor cells to tumors. Cancer Res 2008, 68:6038-6042.

6. Su Y, Zheng L, Wang Q, Li W, Cai Z, Xiong S, Bao J: Quantity and clinical relevance of circulating endothelial progenitor cells in human ovarian cancer. J Exp Clin Cancer Res 2010, 29:27-34

7. Risau W: Mechanisms of angiogenesis. Nature 1997, 386:671-674.

8. Masuda H, Asahara T: Post-natal endothelial progenitor cells for neovascularization in tissue regeneration. Cardiovasc Res 2003, 58:390-398.

9. Asahara T, Murohara T, Sullivan A, Silver M, Van der Zee R, Li T, Witzenbichler B, Schatteman G, Isner JM: Isolation of putative progenitor endothelial cells for angiogenesis. Science 1997, 275:964-967.

10. Khakoo AY, Finkel T: Endothelial progenitor cells. Annu Rev Med 2005, 56:79-101.

11. Rehman J, Li J, Orschell CM, March KL: Peripheral blood "endothelial progenitor cells" are derived from monocytes/macrophages and secrete angiogenic growth factors. Circulation 2003, 107:1164-1169.

12. Fang D, Xiao-qin $\mathrm{H}$ : Effect of endothelial progenitor cells in neovascularization and their application in tumor therapy. Chin Med J 2010, 123(17):2454-2460.

13. Timmermans F, Plum J, Yoder MC, Ingram DA, Vandekerckhove B, Case J: Endothelial progenitor cells: identity defined? J Cell Mol 2009, 13:87-102.

14. Yoder MC, Mead LE, Prater D, Krier TR, Mroueh KN, Li F, Krasich R, Temm CJ, Prchal JT, Ingram DA: Redefining endothelial progenitor cells via clonal analysis and hematopoietic stem/progenitor cell principals. Blood 2007, 109:1801-1809.

15. Hristov M, Zernecke A, Liehn EA, Weber C: Regulation of endothelial progenitor cell homing after arterial injury. Thromb Haemost 2007, 98:274-277.

16. Asahara T, Masuda H, Takahashi T, Kalka C, Pastore C, Silver M, Kearne M, Magner M, Isner JM: Bone marrow origin of endothelial progenitor cells responsible for postnatal vasculogenesis in physiological and pathological neovascularization. Circ Res 1999, 85:221-228.

17. Wels J, Kaplan RN, Rafii S, Lyden D: Migratory neighbors and distant invaders: tumor-associated niche cells. Genes Dev 2008, 22(5):559-574.

18. Heissig B, Hattori K, Dias S, Friedrich M, Ferris B, Hackett NR, Crystal RG, Besmer P, Lyden D, Moore MA, Werb Z, Rafii S: Recruitment of stem and progenitor cells from the bone marrow niche requires MMP- 9 mediated release of kit-ligand. Cell 2002, 109(5):625-637.

19. Liu ZJ, Velazquez OC: Hyperoxia, endothelial progenitor cell mobilization, and diabetic wound healing. Antioxid Redox Signal 2008, 10:1869-1882.

20. Janic B, Arbab AS: The role and therapeutic potential of endothelial progenitor cells in tumor neovascularization. ScientificWorldJournal 2010, 10:1088-1099.

21. Ribatti D: The involvement of endothelial progenitor cells in tumor angiogenesis. J Cell Mol Med 2004, 8:294-300.

22. Salcedo R, Young HA, Ponce ML, Ward JM, Kleinman HK, Murphy WJ, Oppenheim JJ: Eotaxin (CCL11) induces in vivo angiogenic responses by human CCR3+ endothelial cells. J Immunol 2001, 166:7571-7578.

23. Lyden D, Hattori K, Dias S, Costa C, Blaikie P, Butros L, Chadburn A, Heissig B, Marks W, Witte L, Wu Y, Hicklin D, Zhu Z, Hackett NR, Crystal RG, 
Moore MAS, Hajjar KA, Manova K, Benezra R, Rafii S: Impaired recruitment of bone-marrow-derived endothelial and hematopoietic precursor cells blocks tumor angiogenesis and growth. Nat Med 2001, 7(11):1194-1201.

24. Nakamura K, Ito Y, Kawano Y, Kurozumi K, Kobune M, Tsuda H, Bizen A, Honmou O, Niitsu Y, Hamada H: Antitumor effect of genetically engineered mesenchymal stem cells in a rat glioma model. Gene Ther 2004, 11:1155-1164.

25. Asahara T, Takahashi T, Masuda H, Kalka C, Chen D, Iwaguro H, Inai Y, Silver M, Isner JM: VEGF contributes to postnatal neovascularization by mobilizing bone marrow-derived endothelial progenitor cells. EMBO J 1999, 18(14):3964-3972.

26. Dery MAC, Michaud MD, Richard DE: Hypoxia-inducible factor 1: regulation by hypoxic and non-hypoxic activators. Int I Biochem Cell Biol 2005, 37:535-540.

27. Nilsson UW, Abrahamsson A, Dabrosin C: Angiogenin regulation by estradiol in breast tissue: tamoxifen inhibits angiogenin nuclear translocation and antiangiogenin therapy reduces breast cancer growth in vivo. Clin Cancer Res 2010, 16(14):3659-3669.

28. Gao X, Hu H, Zhu J, Xu Z: Identification and characterization of follistatin as a novel angiogenin-binding protein. FEBS Lett 2007, 581:5505-5510.

29. Krneta J, Kroll J, Alves F, Prahst C, Sananbenesi F, Dullin C, Kimmina S, Phillips DJ, Augustin HG: Dissociation of angiogenesis and tumorigenesis in follistatin- and activin-expressing tumors. Cancer Res 2006, 66:5686-5695.

30. Stoeltzing O, Ahmad SA, Liu W, McCarty MF, Wey JS, Parikh AA, Fan F, Reinmuth N, Kawaguchi M, Bucan CD, Ellis LM: Angiopoietin-1 inhibits vascular permeability, angiogenesis, and growth of hepatic colon cancer tumors. Cancer Res 2003, 63:3370-3377.

31. Saharinen P, Bry M, Alitalo K: How do angiopoietins Tie in with vascular endothelial growth factors? Curr Opin Hematol 2010, 17:198-205.

32. Laurén J, Gunji Y, Alitalo K: Is angiopoietin-2 necessary for the initiation of tumor angiogenesis? Am J Pathol 1998, 153(5):1333-1337.

33. Natori T, Sata M, Washida M, Hirata Y, Nagai R, Makkuchi M: G-CSF stimulates angiogenesis and promotes tumor growth: potential contribution of bone marrow-derived endothelial progenitor cells. Biochem Biophys Res Commun 2002, 297:1058-1061.

34. Li A, Dubey S, Varney ML, Dave BJ, Singh RK: IL-8 directly enhanced endothelial cell survival, proliferation, and matrix metalloproteinases production and regulated angiogenesis. J Immunol 2003, 170(6):3369-3376.

35. Schömig K, Busch G, Steppich B, Sepp D, Kaufmann J, Stein A, Schömig A, Ott I: Interleukin-8 is associated with circulating CD133+ progenitor cells in acute myocardial infarction. Eur Heart J 2006, 27:1032-1037.

36. Razmkhah M, Jaberipour M, Hosseini A, Safaei A, Khalatbari B, Ghaderi A: Expression profile of IL-8 and growth factors in breast cancer cells and adipose-derived stem cells (ASCs) isolated from breast carcinoma. Cell Immunol 2010, 265:80-85

37. Schober A: Chemokines in vascular dysfunction and remodeling. Arterioscler Thromb Vasc Biol 2008, 28(11):1950-1959.

38. Du R, Lu KV, Petritsch C, Liu P, Ganss R, Passegué E, Song H, Vandenberg S, Johnson RS, Werb Z, Bergers G: HIF1alpha induces the recruitment of bone marrow-derived vascular modulatory cells to regulate tumor angiogenesis and invasion. Cancer Cell 2008, 13(3):206-220.

39. Aiuti A, Webb IJ, Bleul C, Springer T, Gutierrez-Ramos JC: The chemokine SDF-1 is a chemoattractant for human CD34+ hematopoietic progenitor cells and provides a new mechanism to explain the mobilization of CD34+ progenitors to peripheral blood. J Exp Med 1997, 185(1):111-120.

40. Duda DG, Fukumura D, Jain RK: Role of eNOS in neovascularization: NO for endothelial progenitor cells. Trends Mol Med 2004, 10(4):143-145.

41. Thum T, Fraccarollo D, Schultheiss M, Froese S, Galuppo P, Widder JD, Tsikas D, Ertl G, Bauersachs J: Endothelial nitric oxide synthase uncoupling impairs endothelial progenitor cell mobilization and function in diabetes. Diabetes 2007, 56:666-674

42. Yin T, Ma X, Zhao L, Cheng K, Wang H: Angiotensin II promotes NO production, inhibits apoptosis and enhances adhesion potential of bone marrow-derived endothelial progenitor cells. Cell Res 2008, 18(7):792-799.

43. Kawamoto A, Asahara T: Role of progenitor endothelial cells in cardiovascular disease and upcoming therapies. Catheter Cardiovasc Interv 2007, 70:477-484.

44. Mikkola T, Turunen P, Avela K, Orpana A, Viinikka L, Ylikorkala O: 17 betaestradiol stimulates prostacyclin, but not endothelin-1, production in human vascular endothelial cells. J Clin Endocrinol Metab 1995, 80(6):1832-1836.

45. Sobrino A, Mata M, Laguna-Fernandez A, Novella S, Oviedo PJ, GarcíaPérez MA, Tarín JJ, Cano A, Hermenegildo C: Estradiol stimulates vasodilatory and metabolic pathways in cultured human endothelial cells. PloS One 2009, 4(12):8242.

46. Hamada H, Kim MK, Iwakura A, Li M, Thorne T, Qin G, Asai J, Tsutsumi $Y_{\text {, }}$ Sekiguchi H, Silver M, Wecker A, Bord E, Zhu Y, Kishore R, Losordo DW: Estrogen receptors $\alpha$ and $\beta$ mediate contribution of bone marrowderived endothelial progenitor cells to functional recovery after myocardial infarction. Circulation 2006, 114:2261-2270.

47. Zhao X, Huang L, Yin Y, Fang Y, Zhao J, Chen J: Estrogen induces endothelial progenitor cells proliferation and migration by estrogen receptors and PI3K-dependent pathways. Microvasc Res 2008, 75:45-52.

48. Imanishi T, Hano T, Nishio I: Estrogen reduces endothelial progenitor cell senescence through augmentation of telomerase activity. $J$ Hypertens 2005, 23(9):1699-1706.

49. Iwakura A, Luedemann C, Shastry S, Hanley A, Kearney M, Aikawa R, Isner JM, Asahara T, Losordo DW: Estrogen-mediated, endothelial nitric oxide synthase-dependent mobilization of bone marrow-derived endothelial progenitor cells contributes to reendothelialization after arterial injury. Circulation 2003, 108:144-150.

50. Masuda H, Kalka C, Takahashi T, Yoshida M, Wada M, Kobori M, Itoh R, Iwaguro H, Eguchi M, Iwami Y, Tanaka R, Nakagawa $Y$, Sugimoto A, Ninomiya S, Hayashi S, Kato S, Asahara T: Estrogen-mediated endothelial progenitor cell biology and kinetics for physiological postnatal vasculogenesis. Circ Res 2007, 101:598-606.

51. Robb AO, Mills NL, Smith IB, Short A, Tura-Ceide O, Barclay GR, Blomberg A, Critchley HO, Newby DE, Denison FC: Influence of menstrual cycle on circulating endothelial progenitor cells. Hum Reprod 2009, 24(3):619-625.

52. Naik RP, Jin D, Chuang E, Gold EG, Tousimis EA, Moore AL, Christos PJ, de Dalmas T, Donovan D, Rafii S, Vahdat LT: Circulating endothelial progenitor cells correlate to stage in patients with invasive breast cancer. Breast Cancer Res Treat 2008, 107(1):133-138.

53. Li A, Cheng XJ, Moro A, Singh RK, Hines OJ, Eibl G: CXCR2-dependent endothelial progenitor cell mobilization in pancreatic cancer growth. Transl Oncol 2011, 4(1):20-28.

54. Isner JM, Asahara T: Angiogenesis and vasculogenesis as therapeutic strategies for postnatal neovascularization. J Clin Invest 1999, 103(9):1231-1236.

55. Young PP, Vaughan DE, Hatzopoulos AK: Biological properties of endothelial progenitor cells (EPCs) and their potential for cell therapy. Prog Cardiovasc Dis 2007, 49(6):412-429.

56. Andreou I, Tousoulis D, Tentolouris C, Antoniades C, Stefanadis C: Potential role of endothelial progenitor cells in the pathophysiology of heart failure: clinical implications and perspectives. Atherosclerosis 2006, 189(2):247-254.

57. Nielson JS, McNagny KM: Novel functions of the CD34 family. J Cell Sci 2008, 121(22):3683-92

58. Sato Y, Kanno S, Oda N, Abe M, Ito M, Shitara K, Shibuya M: Properties of two VEGF receptors, Flt-1 and KDR, in signal transduction. Ann N Y Acad Sci 2000, 902:201-205.

59. Holmes K, Roberts OL, Thomas AM, Cross MJ: Vascular endothelial growth factor receptor-2: structure, function, intracellular signaling and therapeutic inhibition. Cell Signal 2007, 19(10):2003-2012.

60. Shmelkov SV, St Clair R, Lyden D, Rafii S: AC133/CD133/Prominin-1. Int J Biochem Cell Biol 2005, 37(4):715-719.

61. Mustelin T, Vang T, Bottini N: Protein tyrosine phosphatases and the immune response. Nat Rev Immunol 2005, 5(1):43-57.

62. Gory-Fauré S, Prandini MH, Pointu H, Roullot V, Pignot-Paintrand I, Vernet M, Huber P: Role of vascular endothelial-cadherin in vascular morphogenesis. Development 1999, 126:2093-2102.

63. Sadler JE: Biochemistry and genetics of von Willebrand factor. Annu Rev Biochem 1998, 67:395-424.

doi:10.1186/1756-8722-4-24

Cite this article as: George et al:: Endothelial progenitor cell biology in disease and tissue regeneration. Journal of Hematology \& Oncology 2011 $4: 24$. 